\title{
Positive Psychologists on Positive Psychology: Sonja Lyubomirsky
}

\author{
Interview by \\ Aaron Jarden
}

\begin{abstract}
Sonja Lyubomirsky is a research psychologist, professor of psychology at the University of California, Riverside, and outgoing editor of the Journal of Positive Psychology. She has spent most of her research career studying human happiness and is author of the popular book The How of Happiness, which describes strategies backed by scientific research that can be used to increase happiness.
\end{abstract}

\section{In general, what are some of the distinctive features of positive psychology?}

Positive psychology is about what makes life worth living. It's about the positive side of life. Before positive psychology, most researchers were focused on studying topics like depression, divorce, stress, how to fix things, and positive psychologists are more interested not in what makes us unhappy, but in what makes us happy. Not why people divorce, but why they stay together. My own research is on 'happiness', which I really started investigating long before the field of positive psychology came into being.

\section{What are some things that positive psychology has achieved to date?}

Maybe the greatest achievement is that it almost does not need to be its own field anymore, because now so many researchers are studying the positive side of life. If you look at any top journal, like in my field, which is social/personality psychology, a huge fraction, sometimes like half, of the articles have something to do with wellbeing or optimism or some kind of positive topic. So it's just pervading the field of psychology. I don't know so much about related fields. We almost don't need to have a separate area called positive psychology, because now it's become part of most people's thinking. It's achieved critical mass.

\section{Can you tell me a bit about your work in positive psychology? You're renowned for your work in the area of positive interventions?}

I started doing research on happiness in 1989, so that was quite a while ago. Just to give you a bit of history, the first day of grad school at Stanford, I met my advisor, Lee Ross, who is famous for studying conflict and negotiation, nothing to do with happiness or positive psychology. The very first day we somehow started talking about 'What is happiness?', and 'Why are some people happier than others?'. At that time the only person-literally the only person - who was studying happiness was Ed Diener, and he didn't even call it happiness, he called it 'subjective wellbeing'. He had told me that at one point that he started to call it subjective wellbeing because he was up for tenure at the University of Illinois and he thought 
that 'happiness' was too unscientific a term, so he had to find a jargon term that was more acceptable. Anyway, Lee and I started investigating 'How are happy people different from unhappy people?', and so for the first ten years of my career, from ' 89 to '99, that's what I did: trying to understand why some people are happier than others.

Most of that research was correlational, so reporters would often call me and ask me, 'Well, what can we tell our readers about how they can be happier?'. So, for example, one of my studies suggested that happier people are less likely to compare themselves to others. So reporters would call me and say, 'Shall we tell people that they should not compare themselves to others, they shouldn't engage in social comparison?'. And I would be like, 'well I don't know! I can't say that because all I know is that happy people do it or don't do it, and that is just a correlational finding'. I thought that the question of how do you get people to do that, or how do you get people to become happier or look more like a happier person was solely an applied question. I thought that was a less interesting scientific question. It was very applied, and I was this basic scientist who was only interested in basic research. But then I realized that the question, 'How can people become happier?' or 'Can people become happier given that a lot of happiness is genetically determined?', was in itself a really interesting scientific question.

In 1999 I was invited to one of the Akumal, Mexico meetings where I met Barbara Fredrickson, Ken Sheldon, Laura King, Jonathan Haidt, and, of course, Martin Seligman and Mike Csikszentmihalyi. That's when we all just started talking, and two of the people there, Ken Sheldon and David Schkade, and I started talking about whether people can even become happier. Scientists up till then had been kind of pessimistic about whether people can really change their happiness set point. So we developed a theory about sustainable happiness. That's more or less how my work in positive interventions started. We had this theory about showing that, yes, people can become happier, and then in the last 10 years of my career, along with Ken Sheldon and others, we have been conducting many happiness interventions. But, again, my interest isn't just applied, so it's not just that I want people to be happier - although I certainly do, it's a nice fringe benefit-but my interest is really more in 'how can people become happier?'. I'm interested in what are the moderators and the mediators underlying success at achieving happiness. What is the 'how' and the 'why'? If people can become happier, why can they do that, and how can they do that? So that's what we are trying to achieve in our research right now, looking at those root psychological mechanisms that enable people to be successful in achieving happiness.

\section{Somebody comes to you and says they want to become happier. What would your first piece of advice to them be?}

People come to me a lot asking that question! I wrote The How of Happiness, where my goal was to basically condense or summarize everything we knew up until then, in 2008, about how to become happier. So what I usually do is send them the 12 empirically-supported categories of strategies or activities that people can do if they want to be happier. I tell them that there is, of course, detailed information about how to become more grateful, or on nurturing their relationships, or pursuing meaningful goals, and I then talk about the research that supports all of these activities or strategies. So that's what I do, I point them to these 12 strategies that I describe in my book. 


\section{Are there any new interventions coming on board that you think are exciting that no one knows about as yet?}

There are certainly some exciting studies that we are doing that I can tell you about. For example, one really exciting project we are working on is with Robert Plomin and his post-doc Claire Hayworth in London. You may know he's a behavioral geneticist, and he has something like 10,000 twins that he's studying and following from birth, just about every twin born in the UK in 1990. We're studying 2,000 of these twins. We've actually just finished the first study, which is a happiness intervention with the twins. There are identical twins and there are fraternal twins in this sample, and there are boys and girls, and so we can answer a lot of questions. What we are interested in in this study is to understand individual differences in people's responses to happiness interventions. How much of those differences are genetic? Because some people, when they try the strategies in my book, find them very effective and they become happier. But some people don't become as happy to the same degree as others, or maybe don't get happier at all. So what portion of those individual differences in people's responses to happiness interventions is genetically determined? We can test that with this twin sample.

\section{What positive psychology activities and strategies do you think work really well together?}

We don't really know the answer to that question. My students and I are actually only just now doing some studies where, in a positive activity intervention, we have people do several activities at the same time. Usually in experiments you want to have everything very controlled, so you study one activity at a time. We've just completed a study where we had people do gratitude and kindness at the same time; but we don't have the results yet. Generally my answer, without the evidence, is that what goes well together is what fits you as a person. One of the themes of my book was the idea of fit. You have to somehow find what works for you and what you feel comfortable doing. For you, it could be one set of interventions, and for me, it could be something else. We are testing this hypothesis right now in a couple of studies.

\section{Where do you see your research going in the future?}

We are still doing quite a few interventions to test 'the how' and 'the why'. I mentioned the study with the twins. We're also doing studies with kids. We just did a big study with a whole bunch of elementary school kids in Vancouver. So I think it's really interesting to apply the research to younger people. My friends keep asking me to write The How of Happiness for kids, because people want their children to be happy so they really want to know. I don't think the advice would be really that different, but we need to find out. There are already some researchers engaged in studying that question. We're doing a lot of that kind of workapplying the interventions to different contexts.

Another line of research that I'm really involved in right now is about hedonic adaptation. Hedonic adaption is an obstacle to happiness; it's an obstacle to happiness interventions. If you adapt and get used to the rewards or benefits of whatever intervention you're engaged in, it's not going to be that successful. Ken Sheldon and I have a theory of how adaptation works, and how you can thwart it, forestall it, or prevent it. We're testing that theory now. Actually a paper that I've submitted with some colleagues about which we are really excited is about whether parents are less happy than non-parents. There have been a lot of articles, a lot of talk in the media about the idea that parents are unhappy, and most of it comes from just one study; and so we did three really nice studies that all used different methodologies, that go together really 
well. All three studies showed the same thing, which is that parents are happier and have more meaning than non-parents-in general, when they are with their children, and when they go about their days. So we're excited because this paper is going to really debunk this myth out there that parents are miserable.

\section{Is there anything that $I$ have not asked about, or general advice, that you would like to add?}

It's so great that there is so much science out there: I think it's really important to emphasize that, because positive psychology is so 'popular', as it were. There are a lot of mental health practitioners and coaches, as well as doctors, addiction specialists, prison guards, who are all applying the concepts of positive psychology, which is great. But we really need the science behind it, and so there are lots and lots of people now doing that research. We need to make sure people know about that, and, as I mentioned before, we almost don't need the field anymore because it has permeated everyone's thinking, so that's important. In terms of people-graduate students or college students - who are interested in getting into the field, I would say the most important thing is not to study positive psychology, but to obtain a really rigorous training in statistics and methodology and general psychology, in whatever area you're interested in, and then you can narrow your interests down to positive psychology.

\section{Author}

Aaron Jarden

Open Polytechnic of New Zealand

aaron.jarden@openpolytechnic.ac.nz 